\title{
Internal Laryngocele Unusual onset in a 91-year-old female patient
}

*Maria C. Spinosi, Chiara Mezzedimi, Giovanni Monciatti, Desiderio Passali

$$
\text { حدوث حالة غير اعتيادية في مريضة عمرها } 91 \text { عامائة }
$$

$$
\text { ماريا سبنوسي، كيارا ميزيديمي، جونفاني مونسياتي، ديزديرو باسالي }
$$

ABSTRACT: While internal laryngoceles rarely cause major clinical complaints, they may lead to airway obstruction and require emergency intervention on rare occasions. We report a 91-year-old patient who was referred to the Ear, Nose \& Throat Clinic of the Policlinico Santa Maria alle Scotte, Siena, Italy, in 2017 due to recurrent episodes of severe dyspnoea. A flexible nasopharyngolaryngoscopic examination revealed an internal laryngocele of approximately $1.5 \mathrm{~cm}$ in diameter that moved up and down the glottic plane, occasionally invading the subglottic space during inspiration and impeding airflow. This caused cyanosis and dyspnoea so severe that an emergency tracheotomy was considered. Luckily, after considerable effort, the patient was able to cough, causing the mass to move above the vocal plane and allowing normal breathing. The laryngocele was subsequently removed via laryngomicrosurgery. Although the incidence of internal laryngoceles is quite rare, physicians should consider this potentially life-threatening condition among patients with dyspnoea.

Keywords: Laryngocele; Dyspnea; Laryngoscopy; Otolaryngology; Case Report; Italy.

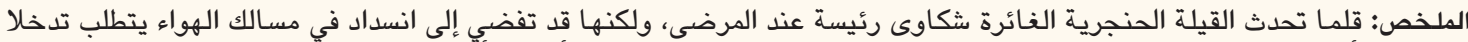

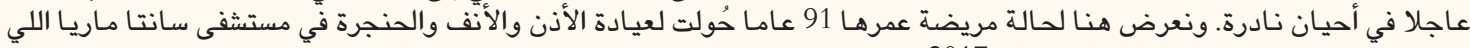

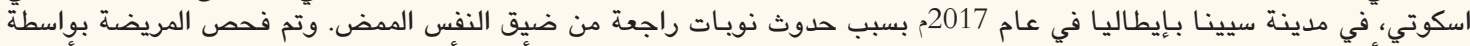

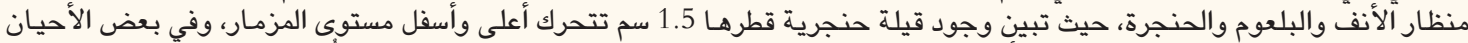

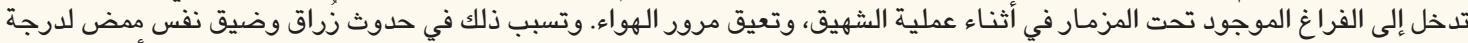

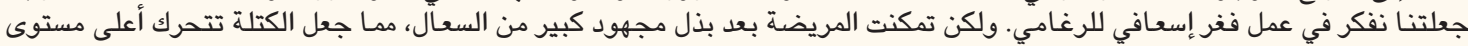

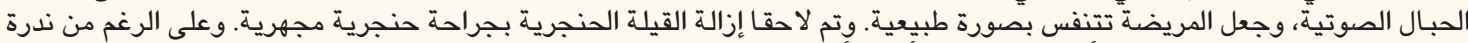

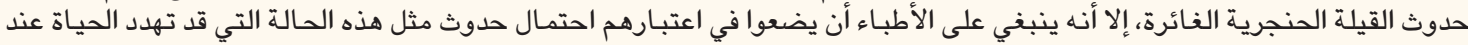
الرضى المصابين بضيق التنفس. الكلمات المفتاحية؛؛ قيلة حنجرية؛ ضيق التنفس؛ تَنْظيرُ الحَنْجَرَ؛ طب الأنف والأذن والحنجرة؛ عرض حالة؛ إيطاليا.

\section{A} LARYNGOCELE IS A RELATIVELY RARE benign dilatation of the laryngeal saccule arising in the region of the laryngeal ventricle; the sac contains air and maintains open communication with the laryngeal lumen. ${ }^{1}$ It occurs in approximately one in 2.5 million cases per year and is usually found in males during the sixth decade of life. Although the exact aetiopathogenesis of laryngoceles has yet to be explained, both congenital and acquired factors are involved. ${ }^{2}$ Laryngoceles can be either internal, external or combined, according to their site; internal laryngoceles are confined to the larynx and do not pierce the thyrohyoid membrane. When the neck of the laryngocele is obstructed, it can fill with mucus and become a laryngomucocele that, if infected, transforms into a laryngopyocele. While this occurs rarely, this severe condition can present with acute airway obstruction and sepsis and may be fatal. ${ }^{3}$
While most laryngoceles are asymptomatic, symptoms can vary according to the type of laryngocele. External laryngoceles usually present as a neck mass that can mimic a neck abscess, lymphadenopathy and saccular, branchial or thyroglossal cysts. ${ }^{2}$ Internal laryngoceles may cause coughing, hoarseness, a sore throat, dysphonia, dysphagia, stridor and even airway obstruction. ${ }^{4,5}$ The Valsalva manoeuvre accentuates the mass, while palpation reduces its volume. Among patients with mixed laryngoceles, the symptoms can be severe, particularly dyspnoea due to the passage of air from the external to the internal component of the laryngocele following compression of the external mass. ${ }^{2}$ Such symptoms may have severe consequences, especially in fragile or elderly patients who often suffer from other comorbidities that may delay diagnosis or complicate management. 


\section{Case Report}

A 91-year-old woman was referred to the Ear, Nose \& Throat (ENT) Clinic of the Policlinico Santa Maria alle Scotte, Siena, Italy, in 2017 due to complaints of dyspnoea and asthaenia. The previous day, she had been admitted to the Casualty Department due to sudden dyspnoea which had begun a few hours previously. She had spent 12 hours in the Casualty Department where she had been diagnosed and treated for a reactivation of known chronic obstructive pulmonary disease. In addition, she reported having an aortic aneurysm. While the patient was cooperative, she was not completely reliable due to slight age-related memory impairment and her poor education level. Her relatives could not be contacted and, in light of her suspected impaired anamnesis, it was not possible to confirm when the symptoms had begun. Electrocardiography findings and the patient's C-reactive protein levels, erythrocyte sedimentation rate and troponin levels were within normal range, while a complete blood count showed $9.93 \times 10^{9} / \mathrm{L}$ white blood cells with $8.48 \times 10^{3}$ neutrophils (85.4\%).

Following several episodes of severe inspiratory dyspnoea and desaturation which resolved spontaneously but kept recurring at progressively shorter intervals, the patient was referred to the ENT Clinic. At referral, she was in a state of eupnoea, but complained of extreme fatigue, mild dysphonia and mild dysphagia. At first, the ENT examination seemed normal; however, during a flexible nasopharyngolaryngoscopic examination, a roundish enlargement of the right false vocal fold was observed, while the ipsilateral true vocal fold could not be visualised. The roundish mass had a diameter of approximately $1.5 \mathrm{~cm}$ and its mucosal surface was smooth. A computed tomography (CT) scan of the neck was scheduled. Before this could be performed, it was noticed that the mass moved up and down the glottic plane, occasionally invading the subglottic space during inspiration and impeding airflow [Figure 1A]. This caused cyanosis and dyspnoea so severe that an emergency tracheotomy was considered.

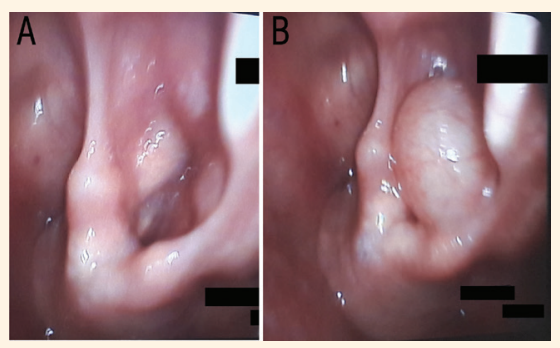

Figure 1: Laryngeal endoscopic photographs of a 91-yearold female patient with recurrent severe dyspnoea showing a laryngocele (A) descending into the trachea and (B) having moved above the vocal folds after coughing.
Fortunately, after considerable effort, the patient was able to cough, causing the mass to move above the vocal plane and allowing normal breathing to resume [Figure 1B].

After obtaining informed consent, the patient was immediately scheduled for surgery. Utilising fiberoptic intubation, the anaesthetist was able to secure the airway without breaking the mass. A microdirect laryngoscopy revealed a roundish mass with a peduncle originating from the anterior third of the ventricle (i.e. the inferior third of the false vocal fold). Along with its base, the mass was completely removed and, upon opening, extruded serous-mucous material. The peduncle region was inspected, but no macroscopic passage connecting it to the ventricle was detected. A histological examination of the specimen revealed that the neoformation had respiratory epithelium compatible with a diagnosis of a laryngocele. No nasogastric feeding tube or tracheotomy was required. The postoperative recovery period was uneventful and a fiberoptic inspection revealed normal healing of the region. Two days later, the patient was discharged without any complications, after which she was sent to the Cardiovascular Unit for examination of the aneurysm. Follow-up appointments at one week, one month and three months showed no recurrence of the laryngocele or the development of any other laryngeal anomalies.

\section{Discussion}

Certain acquired or environmental factors have been implicated in the aetiopathogenesis of laryngoceles, including as an occupational hazard among wind instrument players or glass blowers and associations with neoplasms of the larynx and atmospheric pressure changes during air travel., ${ }^{1,6}$ In turn, congenital laryngoceles have been reported to cause newborn respiratory distress that may lead to death. ${ }^{7}$ In this particular case, the cause of the laryngocele could not be determined. The age of the patient prevented any stressful activity and there was no history of any previous episodes of acute dyspnoea, dysphagia or a sore throat. In addition, the patient did not smoke and there was no evidence of a laryngeal carcinoma.

Internal laryngoceles may cause severe symptoms, with particularly serious consequences in fragile or elderly patients, as in the present case. In fact, even though laryngocele surgeries are usually elective, the current patient required urgent management due to the extreme severity of her dyspnoea, for which an emergency tracheotomy was considered. ${ }^{8}$ Imaging is essential for the diagnosis of a laryngocele. Overall, CT scans are the most effective method to determine the type, location and extent of the laryngocele and 
for treatment planning in conjunction with a laryngoscopy and/or laryngostroboscopy. ${ }^{9}$ Due to its widespread availability, CT is the most popular modality for general laryngeal imaging, whereas magnetic resonance imaging is used as a problem-solving tool and ultrasonography can be helpful in the assessment of a laryngeal lesion. ${ }^{9}$ However, CT is the most accurate radiological method of defining spatial relationships between the laryngocele, laryngeal structures and extralaryngeal tissues as well as excluding carcinomas during the differential diagnosis. ${ }^{10,11}$ In the current case, a CT scan was not performed prior to surgery due to the patient's extreme dyspnoea and age-related fragility.

While surgery is considered the treatment of choice for laryngocele cases, the approach essentially depends on the size of the lesion., ${ }^{42}$ Small internal laryngoceles should be excised endoscopically with a carbon dioxide laser or by laryngomicrosurgery using an oral approach under general anaesthesia, since a minimally invasive approach allows for a safer surgery and quicker recovery, as in the current case. ${ }^{13,14}$ Large internal, external or mixed laryngoceles should be treated either via an external surgery (i.e. a laryngofissure or lateral thyroidotomy) or a combined approach., ${ }^{2,8}$

Recently, transoral robotic surgery has been reported to reduce morbidity and preserve the glottic space and vocal function, even for combined laryngoceles extending deep within the neck. ${ }^{15}$ Moreover, this type of surgery has been found to be superior to classical methods in terms of safety, technical feasibility and curative effectiveness, in part because of the absence of skin incisions. ${ }^{16}$ Unfortunately, the robotic equipment necessary for such surgeries is not yet available in every hospital. In general, the success of surgical procedures in laryngocele cases depends upon the accurate delineation of the neck of the sac within the ventricle and the correct identification of the dissection plane between the sac and surrounding tissue; the latter factor may be challenging, especially in emergency cases. ${ }^{14}$

\section{Conclusion}

Although the surgical treatment of laryngoceles is usually elective, patients may nevertheless require emergency interventions such as a tracheotomy. In rare cases, the internal part of the laryngocele may cause rapid and complete airway obstruction with potentially fatal consequences. Although the incidence of internal laryngoceles is relatively rare, physicians should include this condition in the differential diagnosis of upper airway problems.

\section{References}

1. Prasad KC, Vijayalakshmi S, Prasad SC. Laryngoceles: Presentations and management. Indian J Otolaryngol Head Neck Surg 2008; 60:303-8. doi: 10.1007/s12070-008-0108-8.

2. Oukessou Y, Abada RL, Roubal M, Mahtar M. Laryngocele: An unusual presentation. Eur Ann Otorhinolaryngol Head Neck Dis 2015; 132:177-8. doi: 10.1016/j.anorl.2015.03.002

3. Byard RW, Gilbert JD. Lethal laryngopyocele. J Forensic Sci 2015; 60:518-20 doi: 10.1111/1556-4029.12676.

4. Prasad N, Singh M, Nagori R, Singh S. Laryngopyocele: Presenting with pressure symptom. Int J Appl Basic Med Res 2015; 5:228-30 doi: $10.4103 / 2229-516 X .165375$.

5. Topal K, Kilic K, Sakat MS, Altaş E, Üçüncü H. Laryngocele causing airway obstruction: A unique case report. West Indian Med J 2016. Epub ahead of print. doi: 10.7727/wimj.2015.340.

6. Butskiy O, Anderson DW. Upper airway obstruction due to a change in altitude: First report in fifty years. J Otolaryngol Head Neck Surg 2016; 45:9. doi: 10.1186/s40463-016-0121-y.

7. Taskinlar H, Vayisoglu Y, Avlan D, Polat A, Nayci A. Congenital laryngomucocele: A rare cause of airway obstruction in a newborn. J Craniofac Surg 2015; 26:e238-40. doi: 10.1097/SCS. 0000000000001543.

8. Zelenik K, Stanikova L, Smatanova K, Cerny M, Kominek P. Treatment of laryngoceles: What is the progress over the last two decades? Biomed Res Int 2014; 2014:819453. doi: 10.11 $55 / 2014 / 819453$

9. Swain SK, Chandra Mallik K, Mishra S, Chandra Sahu M. Laryngocele: Experience at a tertiary care hospital of Eastern India. J Voice 2015; 29:512-16. doi: 10.1016/j.jvoice.2014.09.013.

10. Storck C, Buitrago-Tellez C. Multidetector computed tomography in nonmalignant laryngeal disease. Curr Opin Otolaryngol Head Neck Surg 2012; 20:443-9. doi: 10.1097/MOO. ob013e328359f358.

11. Töro K, Kardos M, Dunay G. Fatal asphyxia due to laryngomucocele. Forensic Sci Int 2009; 190:e1-4. doi: 10.1016/j.fors ciint.2009.05.002

12. Mobashir MK, Basha WM, Mohamed AE, Hassaan M, Anany AM. Laryngoceles: Concepts of diagnosis and management. Ear Nose Throat J 2017; 96:133-8.

13. Kusunoki T, Wada R, Homma H, Kidokoro Y, Yanai A, Ikeda K. Two cases of the laryngeal cystic lesions. Clin Pract 2016; 6:822. doi: $10.4081 /$ cp.2016.822

14. Fox R, Ramdoo K, Tatla T. Endoscopic CO2 laser excision of a ruptured laryngocele: A novel 'blue-dye' technique to assist dissection and avoid recurrent laryngeal nerve injury. Clin Otolaryngol 2017; 42:957-8. doi: 10.1111/coa.12503.

15. Ciabatti PG, Burali G, D’Ascanio L. Transoral robotic surgery for large mixed laryngocoele. J Laryngol Otol 2013; 127:435-7. doi: 10.1017/S0022215113000236.

16. Kayhan FT, Güneş S, Koç AK, Yiğider AP, Kaya KH. Management of laryngoceles by transoral robotic approach. J Craniofac Surg 2016; 27:981-5. doi: 10.1097/SCS.0000000000002641. 